\title{
Why is Trichodesmium abundant in the Kuroshio?
}

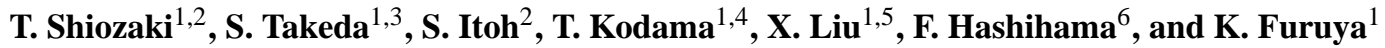 \\ ${ }^{1}$ Department of Aquatic Bioscience, Graduate School of Agricultural and Life Sciences, \\ The University of Tokyo, Tokyo, 113-8657, Japan \\ ${ }^{2}$ Atmosphere and Ocean Research Institute, The University of Tokyo, Chiba, 277-8564, Japan \\ ${ }^{3}$ Faculty of Fisheries, Nagasaki University, Nagasaki, 852-8521, Japan \\ ${ }^{4}$ Japan Sea National Fisheries Research Institute, Fisheries Research Agency, Niigata, 951-8121, Japan \\ ${ }^{5}$ College of Ocean and Earth Sciences, Xiamen University, Xiamen, 361005, China \\ ${ }^{6}$ Department of Ocean Sciences, Tokyo University of Marine Science and Technology, Tokyo, 108-8477, Japan \\ Correspondence to: T. Shiozaki (shiozaki@aori.u-tokyo.ac.jp)
}

Received: 13 June 2015 - Published in Biogeosciences Discuss.: 16 July 2015

Revised: 17 November 2015 - Accepted: 22 November 2015 - Published: 4 December 2015

\begin{abstract}
The genus Trichodesmium is recognized as an abundant and major diazotroph in the Kuroshio, but the reason for this remains unclear. The present study investigated the abundance of Trichodesmium spp. and nitrogen fixation together with concentrations of dissolved iron and phosphate in the Kuroshio and its marginal seas. We performed the observations near the Miyako Islands, which form part of the Ryukyu Islands, situated along the Kuroshio, since our satellite analysis suggested that material transport could occur from the islands to the Kuroshio. Trichodesmium spp. bloomed (> 20000 filaments $\mathrm{L}^{-1}$ ) near the Miyako Islands, abundance was high in the Kuroshio and the Kuroshio bifurcation region of the East China Sea, but was low in the Philippine Sea. The abundance of Trichodesmium spp. was significantly correlated with the total nitrogen fixation activity. The surface concentrations of dissolved iron (0.19$0.89 \mathrm{nM})$ and phosphate $(<3-36 \mathrm{nM})$ were similar for all of the study areas, indicating that the nutrient distribution could not explain the spatial differences in Trichodesmium spp. abundance and nitrogen fixation. Numerical particle-tracking experiments simulated the transportation of water around the Ryukyu Islands to the Kuroshio. Our results indicate that Trichodesmium growing around the Ryukyu Islands could be advected into the Kuroshio.
\end{abstract}

\section{Introduction}

The Kuroshio is a western boundary current in the North Pacific Ocean that originates in the North Equatorial Current and bifurcates to the east of the Philippines. The main stream of the Kuroshio enters the East China Sea (ECS) northeast of Taiwan, flows out through the Tokara Strait, and runs along the Japanese islands of Shikoku and Honshu. While the Kuroshio and its adjacent waters are characterized by highly oligotrophic conditions, phytoplankton and zooplankton communities in the Kuroshio are distinct compared to those from adjacent waters (McGowan, 1971). McGowan (1971) suggested that some plankton species are delivered by the Kuroshio to the north from the equatorial region.

The abundance of the cyanobacterial genus Trichodesmium in the Kuroshio is much higher than that in neighboring seas (Marumo and Asaoka, 1974). Because Trichodesmium is a major nitrogen fixer in the Kuroshio, it is believed to be the key genus for understanding the Kuroshio ecosystem (Chen et al., 2008, 2014; Shiozaki et al., 2014a). Nevertheless, the factors controlling the distribution of Trichodesmium in this region are poorly understood. Marine nitrogen fixation is thought to be regulated by the supply of iron and phosphorus (Mahaffey et al., 2005), and Trichodesmium thrives in iron-rich oligotrophic regions (Moore et al., 2009; Shiozaki et al., 2010, 2014b). A major source of iron in the ocean is atmospheric dust deposition (Jickells et al., 2005; Mahowald et al., 2009). Modeling studies indicate 

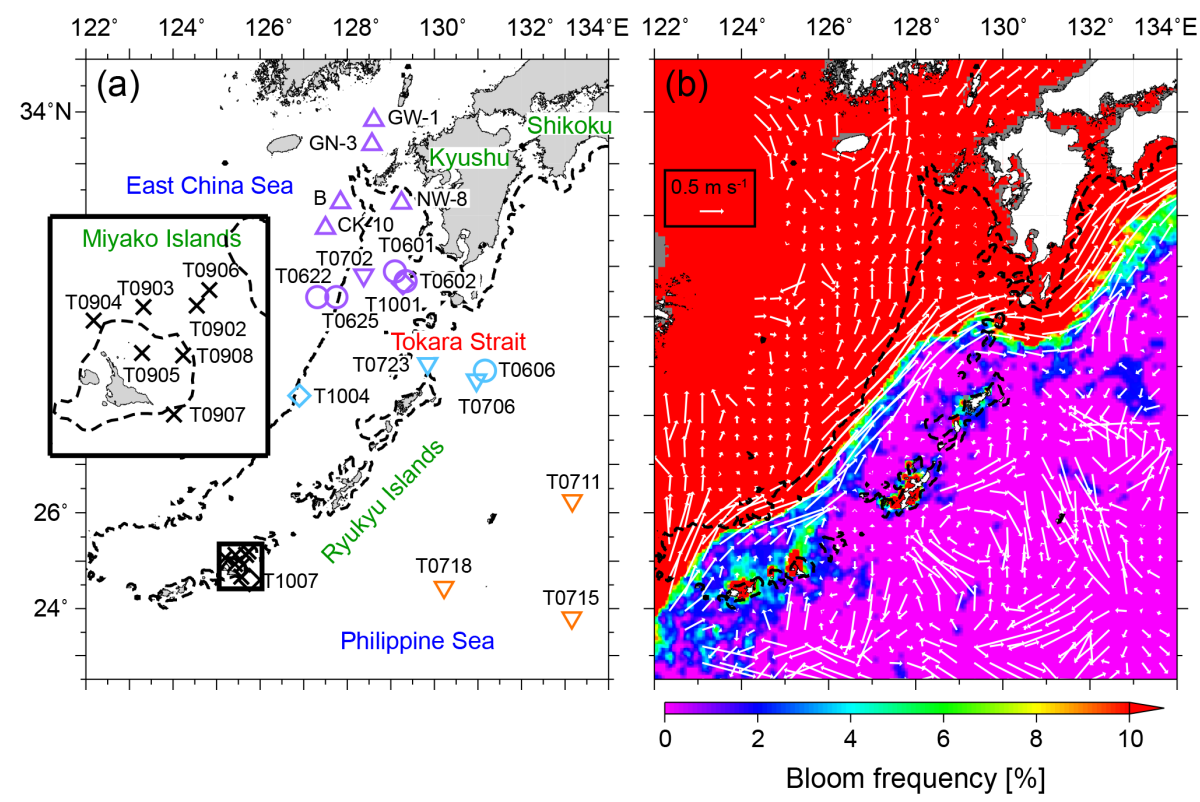

Figure 1. (a) Sampling stations during the KT-06-21 (circles), KT-07-22 (inverted triangles), KT-09-17 (crosses), KT-10-19 (diamonds), and 242 (triangles) cruises. Symbols of stations located in the East China Sea, the Kuroshio, the Philippine Sea, and near the Miyako Islands are indicated in purple, light blue, orange, and black, respectively. (b) Climatological surface current fields during summer (1953-2008) from geoelectrokinetograph measurements and ship-mounted ADCP data. The background contour represents the percentage of chlorophyll $a$ of $>0.15 \mathrm{mg} \mathrm{m}^{-3}$ during summer between 2003 and 2009. Dashed lines indicate $200 \mathrm{~m}$ isobaths.

that dust deposition in the western North Pacific decreases exponentially from the continental shelf to the Philippine Sea (Jickells et al., 2005; Mahowald et al., 2009); hence, deposition is not as high in the Kuroshio as in the adjacent waters. As for phosphorus limitation, iron-enhanced nitrogen fixation causes phosphorus depletion, and the nitrogen fixation is consequently limited by phosphorus (Mather et al., 2008). The phosphate distribution has been examined in this study region using a conventional colorimetric method, and the surface phosphate concentration in the Kuroshio has been reported to be as low as that in the Philippine Sea (Chen, 2008). Therefore, the distinct high abundance of Trichodesmium in the Kuroshio is probably not explained by nutrient and trace metal concentrations; however, distributions of dissolved iron and phosphate at the nanomolar level have not been well studied in this region (Obata et al., 1997; Shiozaki et al., 2010; Kodama et al., 2011).

Nitrogen fixation by Trichodesmium has recently also been found to be active around oceanic islands: New Caledonia, Efate, Fiji, Tahiti, and the Northern Mariana Islands (Shiozaki et al., 2010, 2013, 2014c; Lin et al., 2011). Furthermore, these studies demonstrated that abundant Trichodesmium is delivered by the current to areas that are remote from the islands. Although this phenomenon was noted in the western Pacific warm pool and western South Pacific, it can also occur in and around the Kuroshio and may contribute to the distribution of Trichodesmium in this region.
In the present study, we simultaneously determined Trichodesmium abundance and bulk water nitrogen fixation together with concentrations of dissolved iron and phosphate at the nanomolar level in the Kuroshio and its marginal seas. In addition, we conducted intensive observations around the Miyako Islands section of the Ryukyu Islands located close to the main stream of the Kuroshio.

\section{Materials and methods}

\subsection{Oceanographic database}

Algal blooms in an oligotrophic region may indicate a nitrogen fixation hotspot (Wilson and Qiu, 2008; Shiozaki et al., 2014c). To identify the locations of intensive algal blooms, we used a data set of chlorophyll (chl) $a$ observed by satellite. According to Wilson and Qiu (2008), an algal bloom in an oligotrophic region can be defined as a surface chl $a$ value $>0.15 \mathrm{mg} \mathrm{m}^{-3}$ in summer. In the present study, we used an 8-day moderate-resolution imaging spectroradiometer (MODIS) Aqua level-3 chl $a$ with $9 \mathrm{~km}$ resolution during summer between July 2003 and September 2009. We defined summer as July through September. The bloom frequency for each pixel was calculated from the ratio of counts in which chl $a$ was $>0.15 \mathrm{mg} \mathrm{m}^{-3}$ to the total counts in which chl $a$ was detected.

To examine the current field, geoelectrokinetograph and ship-mounted acoustic Doppler current profiler (ADCP) data from the uppermost layer for the summers between 1953 
and 2008 were obtained from the Japan Oceanographic Data Center (http://www.jodc.go.jp). Regridding, removal of anomalous values, and smoothing of the data set were performed as described by Isobe (2008).

\subsection{Cruise observations}

Experiments were conducted during summer on-board the R/V Tansei-maru (KT-06-21, 9-17 September 2006; KT-0722, 5-13 September 2007; KT-09-17, 8-13 September 2009; KT-10-19, 4-12 September 2010) and the T/V Nagasakimaru (242, 19-28 July 2007) (Fig. 1a, Table S1 in the Supplement). The stations during the KT-06-21, KT-07-22, and Nagasaki-maru 242 cruises were divided into three areas based on the temperature-salinity diagram (see Fig. 2 of Shiozaki et al., 2011): the ECS, Kuroshio, and Philippine Sea. During the KT-09-17 cruise, we conducted experiments around the Miyako Islands, which were distinguished from the other three areas. During the KT-10-19 cruise, we performed observations in the ECS, the Kuroshio, and around the Miyako Islands (Liu et al., 2013).

\subsubsection{Light intensity, hydrography, nutrients, and chl $a$}

Water samples for all of the experiments, with the exception of determination of the dissolved iron concentration, were collected using an acid-cleaned bucket and Niskin-X bottles. The depth profile of light intensity was determined immediately before the water sampling using a light sensor (during the KT-06-22, KT-07-21, KT-09-17, and KT-10-19 cruises) or an empirical equation (during the Nagasaki-maru 242 cruise) (Shiozaki et al., 2011). Temperature and salinity profiles to a depth of $200 \mathrm{~m}$ were obtained using a conductivity, temperature, and depth (CTD) sensor. Mixed layer depth (MLD) was defined as the depth at which the sigma- $t$ increased by 0.125 from its value at a depth of $10 \mathrm{~m}$. Water samples for nitrate + nitrite $(\mathrm{N}+\mathrm{N})$ and phosphate were collected from $0,10,30,40,50,60,70,80,90,100,125,150$, and $200 \mathrm{~m}$, and from depths at given light intensities. At all of the stations, the $\mathrm{N}+\mathrm{N}$ and phosphate concentrations were determined at the nanomolar level using a supersensitive colorimetric system consisting of an AutoAnalyzer II (Technicon) and Liquid Waveguide Capillary Cells (World Precision Instruments, USA) (Hashihama et al., 2009). The detection limits of $\mathrm{N}+\mathrm{N}$ and phosphate were both $3 \mathrm{nM}$. When the concentration was greater than $0.1 \mu \mathrm{M}$, it was determined by conventional methods using a TRAACS 2000 autoanalyzer (Bran+Luebbe, UK). In addition to the observations at the stations, temperature, salinity, and the in vivo chl fluorescence of the surface water were monitored continuously during the cruises by a thermosalinograph (Ocean Seven, Idronaut, Italy) and a fluorometer (Minitracka, Chelsea, UK).

\subsubsection{Dissolved iron}

Water was sampled to estimate the dissolved iron concentration from $0.5 \mathrm{~m}$ depth during the KT-06-21 and KT-07-22 cruises and from $10 \mathrm{~m}$ depth during the KT-09-17 cruise using an acid-cleaned Teflon bellows pump (AstiPure PFD2; Saint-Gobain) with Teflon tubing (inner diameter $=12 \mathrm{~mm}$ ). The water was filtered through an acid-cleaned $0.22 \mu \mathrm{m}$ pore filter (Millipak100; Millipore) connected to the in-line of the Teflon tubing with a Teflon connector. Filtered seawater was collected in a $125 \mathrm{~mL}$ low-density polyethylene (LDPE) bottle (Nalgene, Nalge Nunc International), which had been washed using following technique: the sample bottles were sequentially cleaned by soaking in $5 \%$ alkali detergent for at least 2 days, in $4 \mathrm{~N} \mathrm{HCl}$ for at least 1 day, in $0.3 \mathrm{~N}$ metal analysis-grade $\mathrm{HNO}_{3}$ at $60^{\circ} \mathrm{C}$ overnight, and, finally, in Milli-Q water at $60^{\circ} \mathrm{C}$ overnight. After rinsing with Milli$\mathrm{Q}$ water, the bottles were dried in a laminar flow space and stored in double plastic bags. The filtrate samples were acidified to a $\mathrm{pH}<1.7$ with trace-metal-grade $\mathrm{HCl}$ (Tamapure AA-100; Tama Chemicals) in a Class-100 clean-air bench, and stored at room temperature for more than 1 year.

The dissolved iron concentration was determined using an automatic $\mathrm{Fe}$ (III) flow injection analytical system (Kimoto Electric Co., Ltd.) using a chelating resin pre-concentration and chemiluminescence detection method (Obata et al., 1993). A buffer solution of $10 \mathrm{M}$ formic acid and $2.4 \mathrm{M}$ ammonium formate was added to the samples. The sample $\mathrm{pH}$ was adjusted to 3.0 with $20 \%$ ammonium hydroxide $\left(\mathrm{NH}_{4} \mathrm{OH}\right.$; Tamapure AA-10; Tama Chemicals) immediately prior to analysis. The detection limit of this method was $0.05 \mathrm{nM}$. The SAFe reference standards S1 and D2 were measured during the course of sample analysis, and the results were within the range of the published consensus values: $\mathrm{S} 1=0.097 \pm 0.043 \mathrm{nM}$ and $\mathrm{D} 2=0.91 \pm 0.17 \mathrm{nM}$ (Johnson et al., 2007).

\subsubsection{Nitrogen fixation and abundance of Trichodesmium spp.}

Samples for the incubation experiments were collected vertically at all of the stations, except at stations T0621, GN-3, and T0905, where samples were only collected from the surface. All samples were collected in duplicate in acid-cleaned 4.5 L polycarbonate bottles. During the Nagasaki-maru 242 cruise, water samples were collected from four different depths corresponding to $100,25,10$, and $1 \%$ of the surface light intensity. During the other cruises, samples were also collected from a depth of $50 \%$ surface light intensity. Samples at $100 \%$ surface light intensity were collected from $0 \mathrm{~m}$ during all of the cruises, except during the KT-10-19 cruise in which the samples were collected from a depth of $5 \mathrm{~m}$. The bulk water nitrogen fixation activity was determined based on primary production using a dual isotopic $\left({ }^{15} \mathrm{~N}_{2}\right.$ and $\left.{ }^{13} \mathrm{C}\right)$ technique (Shiozaki et al., 2009). After ${ }^{13} \mathrm{C}$-labeled sodium 
bicarbonate (99 at. $\%{ }^{13} \mathrm{C}$; Cambridge Isotope Laboratories) was added to each bottle, $2 \mathrm{~mL}$ of ${ }^{15} \mathrm{~N}_{2}$ gas $\left(98\right.$ at. $\%{ }^{15} \mathrm{~N}$; SI Science Co. Japan) was injected directly into the incubation bottles through a septum using a gastight syringe. The bottles were covered with neutral-density screens to adjust the light level and incubated for $24 \mathrm{~h}$ in an on-deck incubator cooled by flowing surface seawater for $24 \mathrm{~h}$. We determined the nitrogen fixation activity using the ${ }^{15} \mathrm{~N}_{2}$ gas bubble addition method (Montoya et al., 1996). This method is believed to underestimate the nitrogen fixation rate relative to the ${ }^{15} \mathrm{~N}_{2}$ gas dissolution method (Mohr et al., 2010). The start time of incubation in this study varied at each station (Table S1). Considering daily periodicity of nitrogen fixation in each diazotroph (Zehr, 2011) and the time to reach equilibration of the ${ }^{15} \mathrm{~N}_{2}$ gas bubble with seawater (> 12 h, Mohr et al., 2010), the level of underestimation could vary at each station. Meanwhile, the level of underestimation is thought to be low in Trichodesmium-dominant water because Trichodesmium can float to the top of the bottle and directly use the added ${ }^{15} \mathrm{~N}_{2}$ in the bubble method (Großkopf et al., 2012). Although the bias of underestimation could not be estimated from the results in this study, the actual nitrogen fixation rate could be higher than the obtained rate.

A recent study demonstrated that commercial ${ }^{15} \mathrm{~N}_{2}$ gas could be contaminated by ${ }^{15} \mathrm{~N}$-labeled nitrate and ammonium (Dabundo et al., 2014). We tested the contamination in ${ }^{15} \mathrm{~N}_{2}$ gas produced by SI Science Co., Ltd., which was used (from different batch numbers) in the present study (see the Supplement). Briefly, the ${ }^{15} \mathrm{~N}_{2}$ gas was dissolved in aged subtropical surface water, and concentrations of nitrate, nitrite, and ammonium at the nanomolar levels were determined using supersensitive colorimetric systems. The results showed that there were no significant differences between the control and samples to which ${ }^{15} \mathrm{~N}_{2}$ had been added (Fig. S1 in the Supplement), suggesting that the contamination of nitrate, nitrite, and ammonium in the ${ }^{15} \mathrm{~N}_{2}$ gas was insignificant (see the Supplement).

Water samples were collected for microscopic analysis at all light depths during the Nagasaki-maru 242 and KT-07-21 cruises, and only from the surface during the KT-06-22, KT09-17, and KT-10-19 cruises. The samples were fixed using acidified Lugol's solution. Trichodesmium spp. were counted using the Utermöhl method under inverted microscope observation. Trichodesmium greater than ca. $300 \mu \mathrm{m}$ in length were counted as 1 filament and shorter lengths were counted as 0.5 filaments. In addition, phytoplankton other than Trichodesmium spp. were identified from the samples obtained during the KT-09-17 cruise.

\subsection{Statistical analysis of environmental variables}

We used non-metric multi-dimensional scaling (nMDS) to investigate the spatial differences in the environmental variables that could influence Trichodesmium growth and bulk water nitrogen fixation: temperature, mixed layer depth, ni- trate, dissolved iron, and phosphate. The environmental variables were transformed by $\log _{10}(x+1)$ prior to analysis. A dissimilarity-similarity matrix between stations was constructed using the Bray-Curtis index. The nMDS was used to visualize similarities in the environmental variables among the stations. An analysis of similarity (ANOSIM) was used to test the differences in the environmental variables among the stations. The nMDS and ANOSIM analyses were performed using PRIMER 6 software.

\subsection{Numerical experiments}

Numerical particle-tracking experiments were conducted to investigate the transport of water masses at the surface from areas around the Miyako Islands in the summer season from 2003 to 2009. Surface velocity data were derived from the FRA-JCOPE2 reanalysis product (Miyazawa et al., 2009), which is an eddy-resolving $\left(1 / 12^{\circ}\right)$ ocean model combined with three-dimensional variational data assimilation (satellites, ARGO floats, and shipboard observations), and is one of the most reliable models for the region around Japan for the above time period. The method of tracking particles was basically the same as in Itoh et al. (2009), but we did not include the random walk for simplicity. The release points of particles were selected at the surface of the model grid points around the coastal waters of the Miyako Islands. We assumed that the particles did not increase, die, or sink from the surface during the experiments. To focus on transport during the summer season (July-September), particles were released one month before the summer ( 1 June) and were tracked until 30 September.

To examine differences in the output depending on the start time within the same year, we also performed experiments starting on 1, 11, and 21 June and 1 July in 2009. The ratio of particles that reached areas downstream of the Tokara Strait (hereafter Area K) (Fig. 7), including the particles' entrainment to the Kuroshio, to total particles released from the Miyako Islands was computed in all experiments. It should be noted that these experiments contained the following two uncertainties. First, the distribution of Trichodesmium around the islands, which strongly influences the destinations of particles, was not able to be determined in advance. Trichodesmium is known to aggregate and not to occur uniformly in the ocean (Capone et al., 1997). Second, the model cannot reproduce the current very close to the islands. If a water mass very near the islands was delivered to the open ocean by tide and/or river plumes that were not considered in the model, seaward dispersion of particles was likely underestimated. 


\section{Results}

\subsection{The Kuroshio path and bloom frequency}

The average surface current field indicated that the main stream of the Kuroshio flowed along the continental shelf in the ECS, and then passed to the south of the Kyushu Islands and Shikoku (Fig. 1b). In addition, the Kuroshio branch bifurcated northward at 25 and $30^{\circ} \mathrm{N}$ at the continental shelf. Hence, all of the stations in the ECS were subject to the influence of the Kuroshio. While the northeastward stream of the Kuroshio was prominent in this region, smaller-scale flows and circulations were observed in the areas around and to the southeast of the Ryukyu Islands. In the west of the main stream of the Kuroshio, because the average chl $a$ was over $0.15 \mathrm{mg} \mathrm{m}^{-3}$ (Fig. S2), the frequency of chl $a$ values $>0.15 \mathrm{mg} \mathrm{m}^{-3}$ was high (Fig. 1b). In contrast, the bloom frequency in the east of the main stream of the Kuroshio differed from the distribution of the average chl $a$; algal blooms occurred frequently in the Ryukyu Islands. Around the Miyako Islands, water of high bloom frequency was located to the west of the islands, extending to the north.

\subsection{Region-wide environmental conditions, Trichodesmium spp., and nitrogen fixation}

The sea surface temperature (SST) ranged from 25.1 to $30.5^{\circ} \mathrm{C}$ at all of the stations (Table S1), and there were no significant differences among the areas ( $p>0.05$, Tukey's honestly significant difference (HSD) test). The MLD varied from 12 to $60 \mathrm{~m}$ at all of the stations, and was relatively deep around the Miyako Islands compared to the other areas (Table $\mathrm{S} 1$ ). The surface $\mathrm{N}+\mathrm{N}$ concentration varied between $<3$ and $42 \mathrm{nM}$, except around the Miyako Islands (Shiozaki et al., 2010, 2011) (Table S1). The highest surface $\mathrm{N}+\mathrm{N}$ concentration ( $374 \mathrm{nM}$ ) was observed at station T0904 where upwelling occurred (see below). No significant difference in the surface $\mathrm{N}+\mathrm{N}$ was observed among the four areas $(p>0.05$, Tukey's HSD test). The surface phosphate concentration varied between $<3$ and $36 \mathrm{nM}$ at all of the stations (Fig. 2a). The phosphate concentrations at the surface and within the MLD were not significantly different among the four areas ( $p>0.05$, Tukey's HSD test). There was a greater increase in the phosphate concentrations below $40-50 \mathrm{~m}$ in the ECS compared to the other areas (Fig. 3a-d). Furthermore, the phosphate concentrations below 40-50 m near the Miyako Islands were higher than those in the Kuroshio and the Philippine Sea, which were depleted down to $100 \mathrm{~m}$, except at station T1004 located near the continental shelf. The N / P $(=\mathrm{N}+\mathrm{N} /$ phosphate $)$ ratio at the surface varied from 0.28 to 6.40 except at station T0904 (N / P = 16.3) (Table S1), and no significant differences were observed among the four areas ( $p>0.05$, Tukey's HSD test). The surface dissolved iron concentration ranged from 0.19 to $0.89 \mathrm{nM}$ at all of the stations (Fig. 2b), with no significant spatial differences among the four areas ( $p>0.05$, Tukey's HSD test). The surface dissolved iron concentrations at stations T0622 and T0907 were elevated to 0.83 and $0.89 \mathrm{nM}$, respectively, with lower salinity water than in the adjacent waters (salinity data are shown in Fig. 4a and Kodama et al., 2011). The nMDS showed that the environmental variables at all stations were the same at the $>80 \%$ similarity level and were $>90 \%$ similar excepting station T0904 (Fig. 5). The ANOSIM indicated no significant differences among the stations $(p>0.05)$.

The abundance of Trichodesmium spp. was highest at the surface at almost all of the stations during the Nagasakimaru 242 and KT-07-21 cruises (Fig. S3). The surface Trichodesmium spp. abundances were positively correlated with the depth-integrated abundances $\left(r^{2}=0.51, p<0.05\right)$ (Fig. 6a). Thus, the surface abundance was used to discuss the geographical distribution of Trichodesmium spp. The Trichodesmium spp. abundance at the surface varied widely, and there was no significant difference among the four areas ( $p>0.05$, Tukey's HSD test). Trichodesmium spp. were observed at all of the stations in the Kuroshio and around the Miyako Islands, whereas they were not always observed in the ECS and the Philippine Sea (Fig. 2c). The average surface abundance in the Philippine Sea was the lowest among all of the areas (Table 1). The highest abundance of Trichodesmium spp. (> 20000 filaments $\mathrm{L}^{-1}$ ) was observed near the Miyako Islands at station T0906, where they bloomed (see below). Tuft-shaped colonies were found at stations T0706, T0723, CK-10, and T0906. The nitrogen fixation rate was highest in the upper $25 \%$ light depth, and decreased with increasing depth at all of the stations (Fig. 3e-h). The surface rates were positively correlated with the depth-integrated rates $\left(r^{2}=0.79, p<0.05\right)$ (Fig. 6b), suggesting that the distribution of nitrogen fixation was indexed by the surface activity. Surface and depth-integrated nitrogen fixation ranged from 0.54 to $62 \mathrm{nmol} \mathrm{NL}^{-1}$ day $^{-1}$ and from 29.5 to $753 \mu \mathrm{mol} \mathrm{N} \mathrm{m}{ }^{-2}$ day $^{-1}$, respectively (Fig. $2 \mathrm{~d}$ and Table S1). Surface nitrogen fixation in the Philippine Sea was significantly lower than that in the Kuroshio $(p<0.05, t$ test).

The surface abundance of Trichodesmium spp. in the entire study area was positively correlated with the nitrogen fixation rate at the surface $\left(r^{2}=0.80 ; p<0.05\left(r^{2}=0.52\right.\right.$; $p<0.05$ if the datum taken at the Trichodesmium-bloom station T0906 is excluded)) (Fig. 6c), suggesting that they significantly contributed to nitrogen fixation in the study region. However, active nitrogen fixation occurred in the ECS where Trichodesmium abundance was low; hence, the other diazotrophs could also be important for nitrogen fixation.

\subsection{Observation around the Miyako Islands during the KT-09-17 cruise}

The SST was lower to the northwest of the Miyako Islands than in adjacent waters, and chl $a$ was enriched in the same location (Fig. 4b, c). Therefore, the enhanced productivity was probably due to nutrient supply by upwelling. This up- 


\section{$\begin{array}{ll}\text { (a) Phosphate [nM] } & \text { (b) Dissolved iron [nM] }\end{array}$}

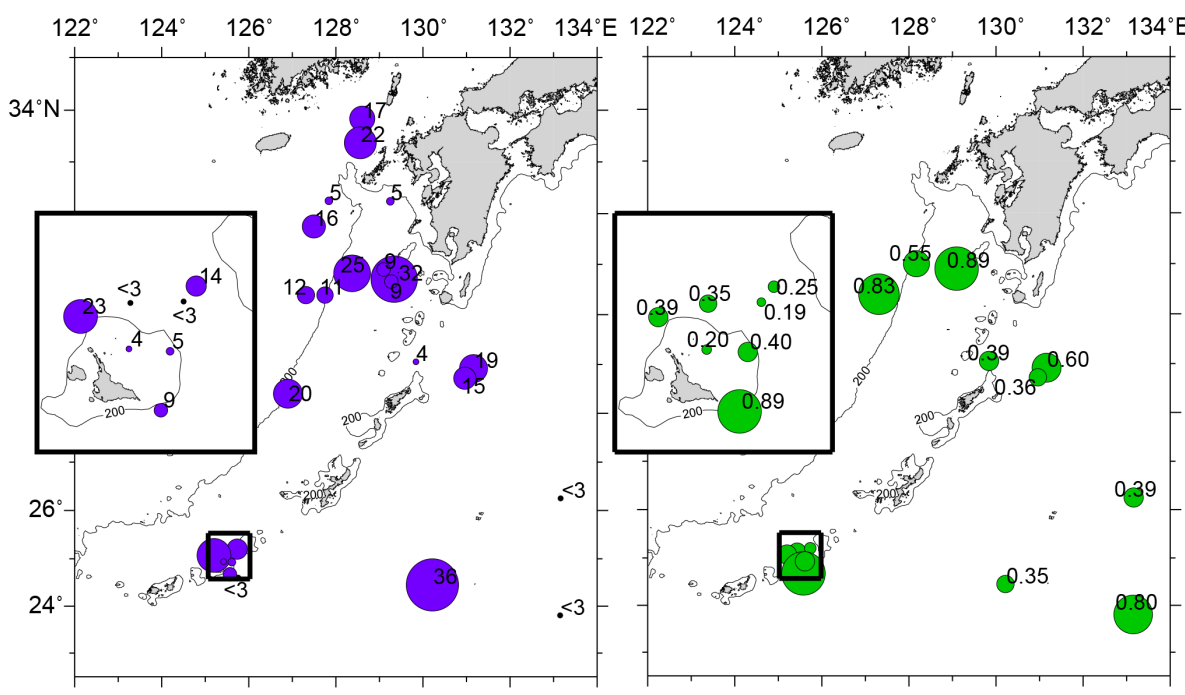

(c) Trichodesmium spp. [filaments $\mathrm{L}^{-1}$ ]

(d) Nitrogen fixation [nmolN L-1 $\mathrm{d}^{-1}$ ]

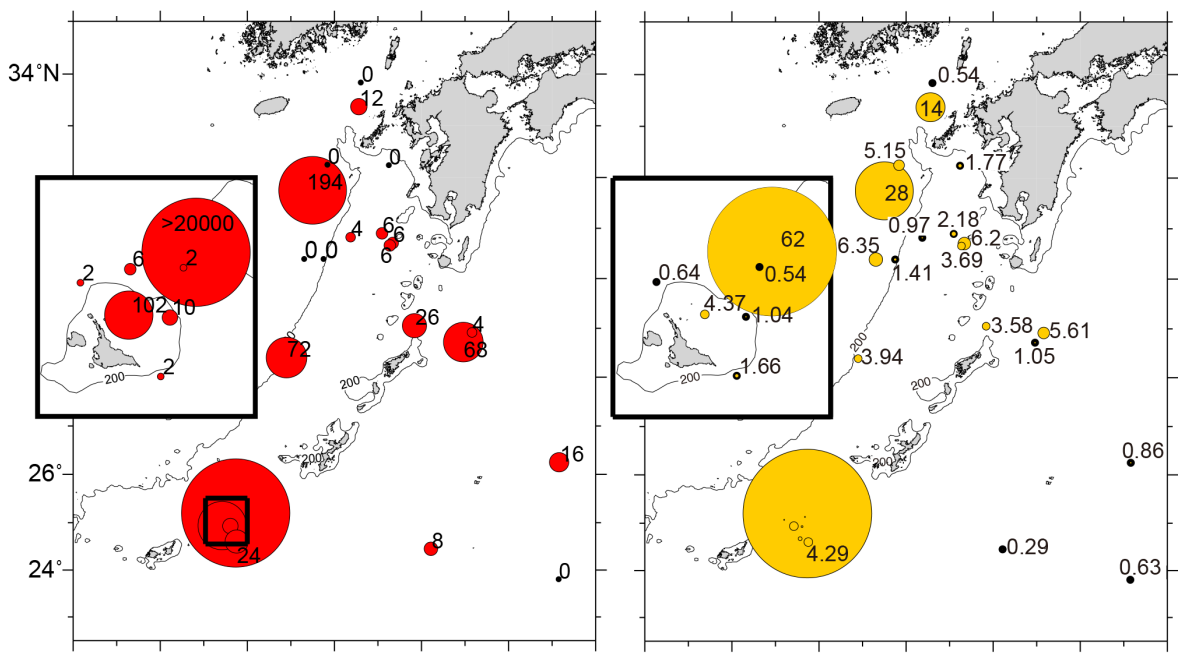

Figure 2. Distribution of (a) phosphate, (b) dissolved iron, (c) Trichodesmium spp., and (d) nitrogen fixation at the surface. The parameters in the small boxes indicate results from the KT-09-17 cruise. The areas of the circles are proportional to the concentration, abundance, or activity.

Table 1. Summary of Trichodesmium at the surface, and depth-integrated nitrogen fixation and its related parameters in the four representative study areas.

\begin{tabular}{lccccccc}
\hline Area & $\begin{array}{c}\text { Trichodesmium } \\
\left(\text { filaments } \mathrm{L}^{-1}\right)\end{array}$ & $\begin{array}{c}\mathrm{N}_{2} \text { fixation } \\
\left(\mu \mathrm{mol} \mathrm{N} \mathrm{L}{ }^{-1} \mathrm{day}^{-1}\right)\end{array}$ & $\begin{array}{c}\text { Temperature* } \\
\left({ }^{\circ} \mathrm{C}\right)\end{array}$ & $\begin{array}{c}\mathrm{MLD} \\
(\mathrm{m})\end{array}$ & $\begin{array}{c}\mathrm{NO}_{3}^{-}+\mathrm{NO}_{2}^{-*, \dagger} \\
(\mathrm{nM})\end{array}$ & $\begin{array}{c}\mathrm{PO}_{4}^{3-*, \dagger} \\
(\mathrm{nM})\end{array}$ & $\begin{array}{c}\mathrm{DFe}^{*} \\
(\mathrm{nM})\end{array}$ \\
\hline East China Sea & $21 \pm 58$ & $170 \pm 140$ & $28.5 \pm 1.2$ & $24 \pm 12$ & $19 \pm 11$ & $15 \pm 9$ & $0.76 \pm 0.18$ \\
Kuroshio & $43 \pm 33$ & $199 \pm 142$ & $29.4 \pm 0.81$ & $27 \pm 8$ & $9 \pm 8$ & $15 \pm 7$ & $0.45 \pm 0.13$ \\
Philippine Sea & $8 \pm 8$ & $58.3 \pm 25.1$ & $29.4 \pm 0.1$ & $23 \pm 3$ & $8 \pm 3$ & $14 \pm 19$ & $0.51 \pm 0.25$ \\
Miyako Islands & $3019 \pm 8478$ & $201 \pm 274$ & $29.3 \pm 0.3$ & $40 \pm 12$ & $61 \pm 128$ & $8 \pm 7$ & $0.38 \pm 0.24$ \\
\hline
\end{tabular}

* values in surface water.

$\dagger$ When the concentration was below the detection limit $(3 \mathrm{nM})$, we assumed a concentration of $3 \mathrm{nM}$ to calculate the mean.

welling generally occurs in the lee of islands (Hasegawa et al., 2009), suggesting that there was a northward current dur- ing the cruise. The surface salinity was lower east of the Miyako Islands than in the surrounding waters (Fig. 4a). The 

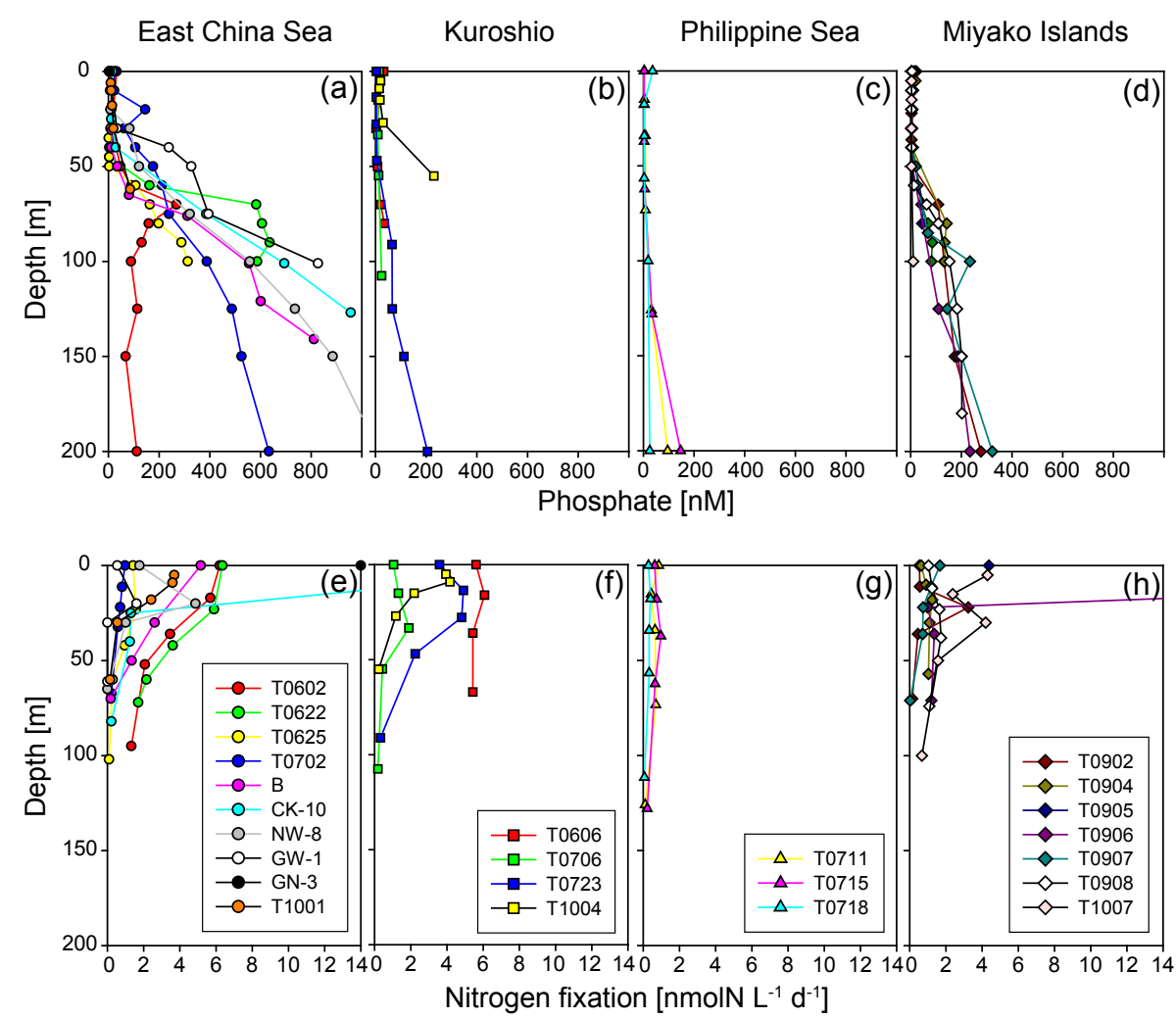

Figure 3. Vertical profiles of phosphate and nitrogen fixation in the East China Sea (a, e), the Kuroshio (b, f), the Philippine Sea (c, g), and the Miyako Islands $(\mathbf{d}, \mathbf{h})$.

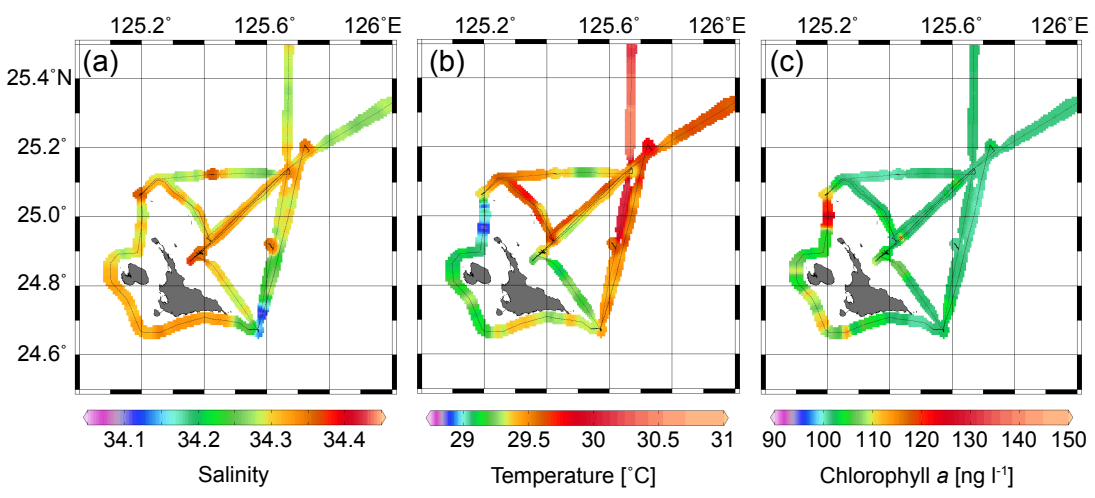

Figure 4. Surface (a) salinity, (b) temperature, and (c) chlorophyll $a$ during the KT-09-17 cruise.

absence of any large river on the east side of Miyako-jima and the separation of low salinity water from the island suggest that the low salinity was caused by rainfall.

Station T0904 was located near the upwelling water; its SST of $29.0^{\circ} \mathrm{C}$ was lowest and its surface $\mathrm{N}+\mathrm{N}$ concentration of $374 \mathrm{nM}$ was highest among all of the stations. However, the $\mathrm{N}+\mathrm{N}$ concentration at station $\mathrm{T} 0904$ at the surface was higher than that at the subsurface (an approximate depth of $50 \mathrm{~m}$; Fig. S4), indicating that station T0904 was not located in the middle of the upwelling. At station T0904, the surface phosphate concentration was also high- est $(23 \mathrm{nM})$ and the $\mathrm{N} / \mathrm{P}$ ratio $(=16.3)$ was higher than the Redfield ratio. With the exception of the surface at station T0904, the phosphate concentration was low $(<3-9 \mathrm{nM})$ in the upper $50 \mathrm{~m}$, with no noticeable variation among the stations (Fig. 2a). The dissolved iron concentration varied between 0.19 and $0.89 \mathrm{nM}$ at the surface (Fig. 2b). The highest dissolved iron concentration was observed at station T0907.

During the same cruise, we encountered a Trichodesmium spp. bloom at station T0906 (Fig. 2c), which had colored water at the surface. The abundance of Trichodesmium spp. at station T0906 was $>20000$ filaments $\mathrm{L}^{-1}$, which was far 


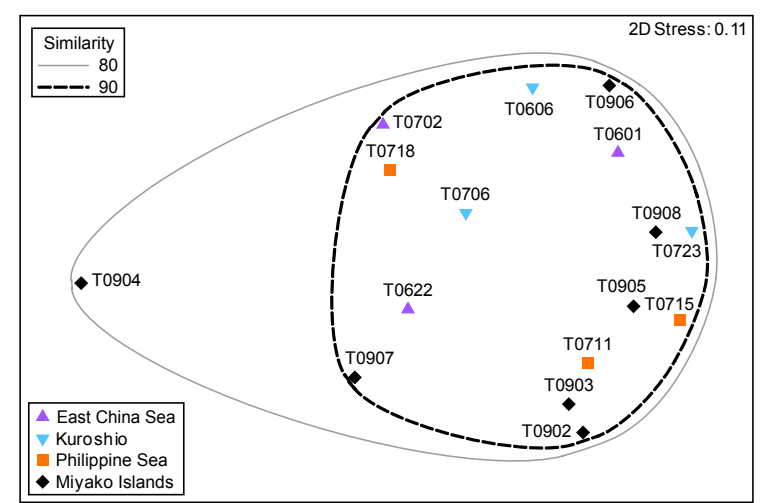

Figure 5. nMDS ordination of sampling stations with environmental variables.

higher than that at other stations (2-102 filaments $\left.\mathrm{L}^{-1}\right)$. The nitrogen fixation rate at the surface $\left(61.9 \mathrm{nmol} \mathrm{N} \mathrm{L}^{-1} \mathrm{~d}^{-1}\right)$ of this station was more than 30 -fold that just below the surface, and was the highest among all of the stations (Fig. 3h). The diatom abundance was markedly higher at station T0904 than that at the other stations. Cylindrotheca closterium was the most numerically dominant diatom $(59 \%)$, followed by Navicula spp. (23\%) and Nitzschia spp. (13\%). C. closterium was not detected at the other stations, indicating that the high chl $a$ induced by the island wake effect mainly consisted of diatoms.

\subsection{Numerical simulation}

As the Kuroshio generally flows along the continental slope north of the Miyako Islands (Fig. 1b), particles around the Miyako Islands were not transported along the typical path of the Kuroshio to the northeast, especially at their initial stages (Fig. 7a). Some particles migrated around the Miyako Islands, or turned south after they passed the Tokara Strait. Nevertheless, the particles delivered to Area K east of the Tokara Strait increased as time elapsed, and the ratio of particles delivered to Area $\mathrm{K}$ to the total released particles ranged from 13 to $56 \%(30 \pm 16 \%)$ by day 120 in $2003-2009$ (Fig. 7b). The year-to-year variations in the ratio are mainly due to influences of mesoscale eddies as partly seen in the particle trajectories in Fig. 7a, and likely occurred over relatively short timescales (shorter than the seasonal timescale). This is supported by another series of experiments in which particles were released on 1, 11, and 21 June and 1 July in 2009 , which yielded ratios of $6.2-38 \%(22 \pm 13 \%)$ by day 120 (Fig. S5).
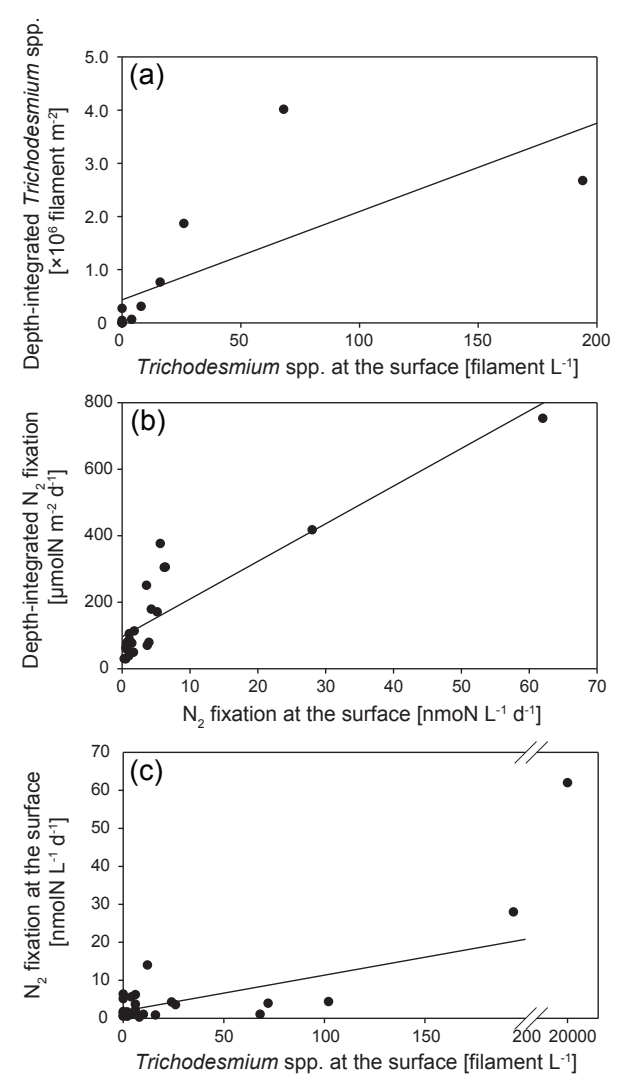

Figure 6. Relationships (a) between surface and depth-integrated Trichodesmium spp. abundance, (b) between surface and depthintegrated nitrogen fixation rates, and (c) between Trichodesmium spp. abundance and nitrogen fixation rate at the surface.

\section{Discussion}

\subsection{Distribution of phosphate and dissolved iron concentrations}

Phosphate concentrations were consistently low within the MLD in all of the studied areas, and the maximum abundance of Trichodesmium spp. and total nitrogen fixation activity generally occurred near the surface, suggesting that the phosphate conditions for surface Trichodesmium spp. and other diazotrophs were similar among all of the areas. Furthermore, with the exception of station T1004 located near the continental shelf, the vertical distribution of phosphate in the Kuroshio was analogous to that in the Philippine Sea. Therefore, at least in the oceanic region of the two areas, phosphate availability for Trichodesmium spp. and the other diazotrophs was similar throughout the water column.

The surface distribution of the dissolved iron concentration demonstrated no significant variation among the areas. The dissolved iron concentration (0.19-0.89 nM) was higher than that in the western North Pacific subtropical region (0.15-0.4 nM) (Brown et al., 2005). Obata et al. (1997) demonstrated that the vertical distribution of the dissolved 
(a)
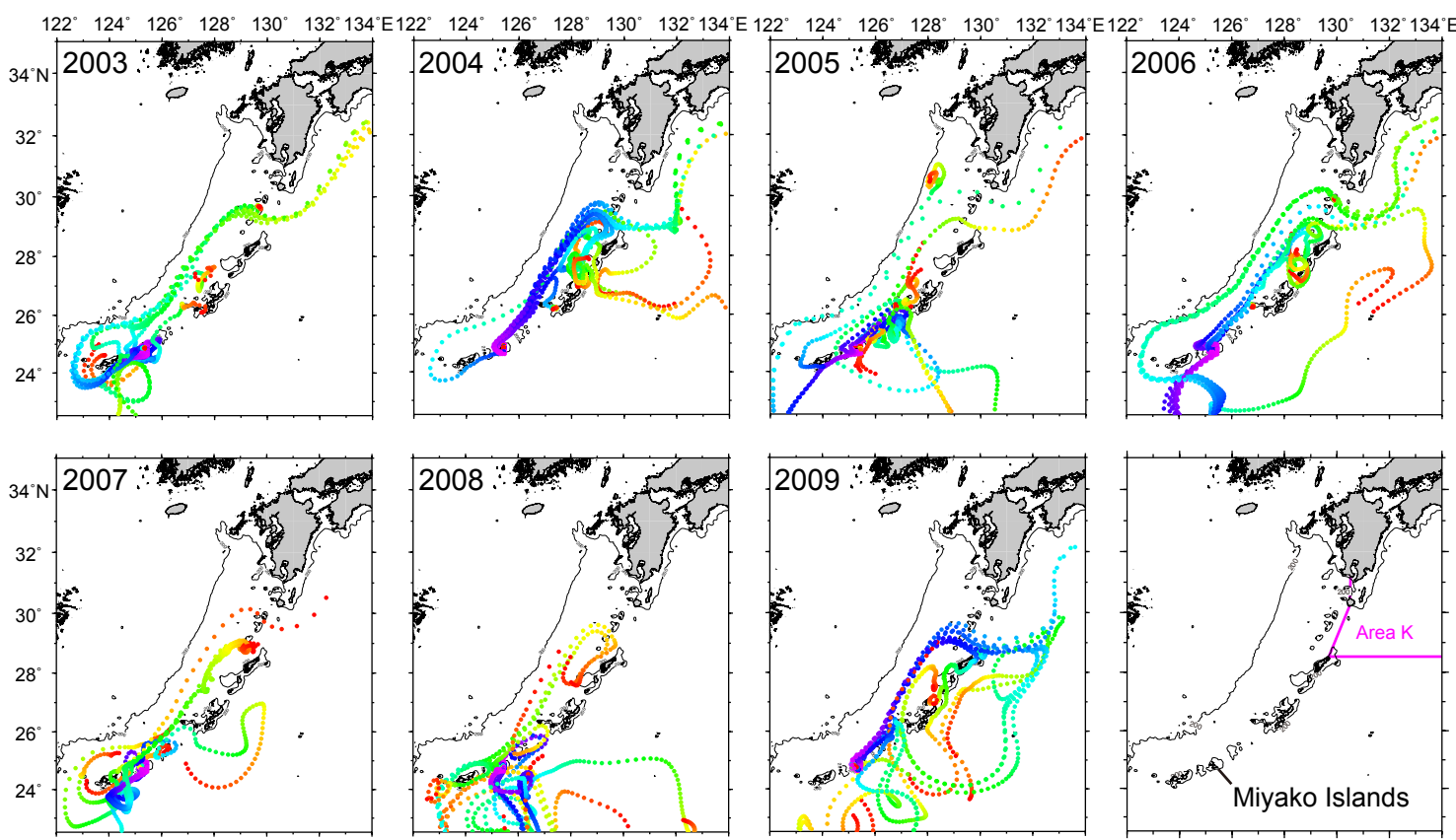

(b)
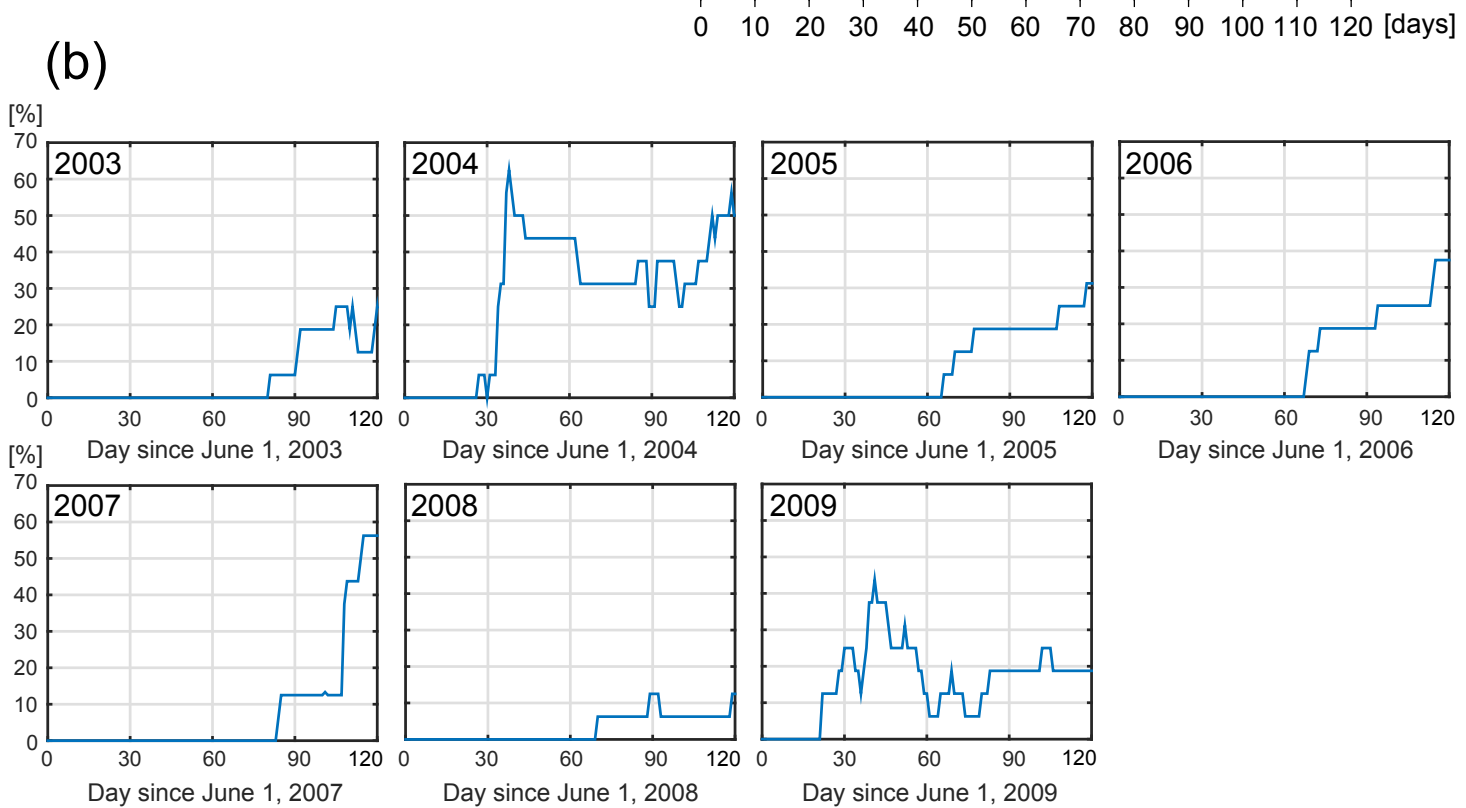

Day since June 1, 2004
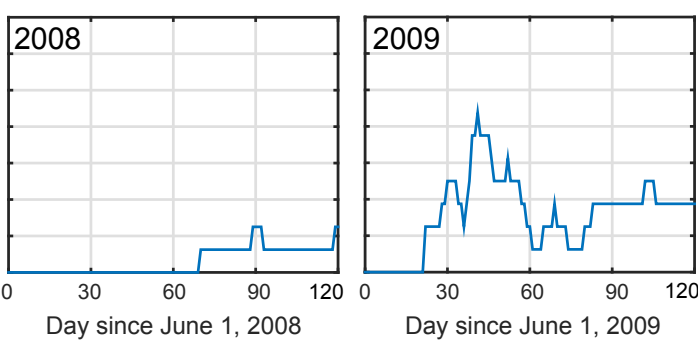

Figure 7. (a) Trajectories of particles released from points around the Miyako Islands on 1 June, 2003-2009. (b) The ratio of particles delivered to Area $\mathrm{K}$ to the total released particles.

iron concentration in the ECS showed two peaks (at the surface and in the deep water), suggesting that aerial dust significantly contributes to the high dissolved iron concentration at the surface in all of our study areas. In accordance with our results, previous modeling studies estimated the amount of dust deposition to be similar in all four areas (Jickells et al., 2005; Mahowald et al., 2009). Therefore, iron availability for
Trichodesmium spp. and the other diazotrophs was also likely similar across all of the study areas. Iron can be supplied from deep water to the surface by mixing processes (Johnson et al., 1999). However, if this were the case, the nitrate concentration would be expected to increase simultaneously at the surface (Johnson et al., 1999), and we observed no noticeable elevation in $\mathrm{N}+\mathrm{N}$ in any of the areas, except at sta- 
tion T0904. High concentrations of dissolved iron $(>0.8 \mathrm{nM})$ corresponded with low salinity at stations T0622 and T0907, suggesting that wet deposition was an important process for iron supply. Dry deposition could also be important since the iron-enriched water at stations T0601 and T0715 did not correspond with low salinity.

Satellite data analysis indicated that there was a "pipeline" of material transport from the Miyako Islands to the Kuroshio, and this was supported by numerical simulations. According to the hypothesis of Marumo and Asaoka (1974), the growth of Trichodesmium in the Kuroshio could be maintained by the supply of iron and phosphorus from the islands situated along the Kuroshio, and the Miyako Islands were considered a possible nutrient source to the Kuroshio. Hence, assuming this hypothesis to be valid, the iron and phosphate concentrations near the Miyako Islands (especially in our observed area) would be expected to be higher than those in the other areas. However, we observed no significant difference in the iron and phosphate concentrations among the four areas. This suggested that there was no detectable washout of iron and phosphorus from the Miyako Islands during our observations, or that diazotrophs and other phytoplankton exhausted the nutrient supply close to the islands.

\subsection{Factors controlling the distributions of Trichodesmium spp. and nitrogen fixation}

Although there was no statistically significant difference in Trichodesmium spp. abundance among the study areas probably because the data were limited and the variation was large, Trichodesmium spp. were always observed in the Kuroshio and were abundant at most stations. Furthermore, at station CK-10 in the East China Sea, which is in the Kuroshio branch current, a high abundance of Trichodesmium spp. was observed. On the other hand, Trichodesmium spp. abundance in the Philippine Sea tended to be lower than in the other areas. Such Trichodesmium distribution was also reported in the previous study (Marumo and Asaoka, 1974). The present study also showed lower surface nitrogen fixation in the Philippine Sea compared to that in the Kuroshio ( $p<0.05, t$ test). Previous studies demonstrated that Trichodesmium spp. flourished in some regions of the subtropical ocean where the iron levels were high (Moore et al., 2009; Shiozaki et al., 2014b), which can be attributed to the high iron requirement of Trichodesmium spp. for their growth compared to other diazotrophs and non-diazotrophs (Kustka et al., 2003; Saito et al., 2011). Therefore, the distribution of Trichodesmium spp. in the study area was expected to be associated with the dissolved iron concentration at the surface. Furthermore, the iron-enhanced active nitrogen fixation causes phosphorus depletion and is consequently limited by phosphorus (Mather et al., 2008). No significant differences in surface iron and phosphate were observed among the study areas, which cannot explain the distribution of Trichodesmium spp. and nitrogen fixation in the study region.
Johnson et al. (1999) reported that the iron supply increased around the continental shelf because re-suspension from the bottom to the euphotic zone becomes significant. However, in the continental shelf of the ECS, the abundance of Trichodesmium spp. and nitrogen fixation were low (Marumo and Asaoka, 1974; Zhang et al., 2012). Zhang et al. (2012) suggested that the low nitrogen fixation in the continental shelf was attributable to mixing processes and the influence of the Yangtze River. Turbulence near the sea floor influences the surface water in the shallower bottom region (Matsuno et al., 2006), and Zhang et al. (2012) suggested that the physical disturbance reduces diazotrophy since diazotrophs including Trichodesmium favor calm seas. Furthermore, the water in the continental shelf of the ECS is strongly influenced by the Yangtze River. The N/P ratio of the Yangtze River plume is significantly higher than the Redfield ratio, which results in phosphorus limitation, and can contribute to the low nitrogen fixation (Zhang et al., 2012). In the present study, despite the fact that the surface phosphate concentration was low throughout the study areas, the N/P ratio was generally lower than the Redfield ratio, suggesting that biological production was limited by the availability of nitrogen compared to phosphate (Moore et al., 2008, 2013). Furthermore, the insignificant difference in MLD among the ECS, the Kuroshio, and the Philippine Sea ( $p>0.05$; Tukey HSD test) indicated similar vertical mixing conditions. Therefore, the environmental variables related to nitrogen fixation only slightly differed as demonstrated by the nMDS plot.

In our study, we found a Trichodesmium spp. bloom near the Miyako Islands. Recent studies demonstrated that Trichodesmium spp. thrived near oceanic islands (Shiozaki et al., 2010, 2014c; Dupouy et al., 2011). Given that some aspect of the environment around the islands increases Trichodesmium spp. abundance and that they are transported from the islands to the Kuroshio, this can explain why the Trichodesmium distribution was not estimated from environmental variables. Accordingly, the low abundance of Trichodesmium spp. in the Philippine Sea was likely due to the low density of islands. Furthermore, higher nitrogen fixation in the Kuroshio than in the Philippine Sea might be explained in the same manner. Trichodesmium is a major nitrogen fixer in the Kuroshio (Chen et al., 2008, 2014; Shiozaki et al., 2014a), and our results showed that the bulk water nitrogen fixation was positively correlated with Trichodesmium abundance.

The numerical simulation demonstrated that released particles from the Miyako Islands were generally transported to the northeast and flowed along the Kuroshio during summer between 2003 and 2009. Thus, if Trichodesmium increases and active nitrogen fixation usually occurs around the Miyako Islands, the water would be delivered to the Kuroshio. Furthermore, we performed additional particletracking experiments whose particle release points were set at major islands in the Ryukyu Islands (Amami Islands, Ok- 
inawa Main Island, and Ishigaki) (Figs. S6 and S7). The results demonstrated that the particles released from the other islands of the Miyako Islands were also delivered to the Kuroshio, with some exceptions. Based on the calculations for $2003-2009,13-56 \%(30 \pm 16 \%)$ of particles released from the islands reached Area K by day 120 (Fig. S7).

Studies on nitrogen fixation around islands in the study region are fairly limited (Liu et al., 2013), and the present study is the first report of a Trichodesmium bloom around islands in the area. The Miyako Islands are surrounded by reefs, and studies have shown that Trichodesmium blooms can be associated with reef environments (Bell et al., 1999; McKinna et al., 2011). However, the factors causing the Trichodesmium blooms around islands are not well understood (Shiozaki et al., 2014c). Further studies are required to identify which characteristics of the near-island environment are important for the growth and/or accumulation of Trichodesmium and other diazotrophs.

\section{Conclusions}

We hypothesize that the high abundance of Trichodesmium spp. and active nitrogen fixation in the Kuroshio were ascribable not to the unique nutrient environment, but rather to the supply of Trichodesmium spp. and other diazotrophs from the surrounding islands. The Ryukyu Islands would not be the only islands with abundant Trichodesmium spp., as Trichodesmium spp. also flourish in the upstream Kuroshio near Luzon (Chen et al., 2008). Therefore, the abundance of Trichodesmium spp. would be generally increased around islands situated along the Kuroshio, and the abundant Trichodesmium spp. would likely be transported to the mainstream of the Kuroshio. Trichodesmium is a major diazotroph in the Kuroshio (Chen et al., 2008, 2014; Shiozaki et al., 2014a), and diazotrophy in the Kuroshio is considered to influence the nutrient stoichiometry in the North Pacific (Shiozaki et al., 2010). Thus, our results indicate that phenomena around the islands located along the Kuroshio are important for determining the partial nitrogen inventory in the North Pacific.

\section{The Supplement related to this article is available online at doi:10.5194/bg-12-6931-2015-supplement.}

Author contributions. T. Shiozaki, S. Takeda, S. Itoh, and K. Furuya designed the experiment; T. Shiozaki, S. Takeda, T. Kodama, X. Liu, F. Hashihama, and K. Furuya collected the samples at sea. T. Shiozaki determined nitrogen fixation and abundance of Trichodesmium spp. during the KT-06-21, KT-07-21, KT-09-17, and Nagasaki-maru 242 cruises, and X. Liu did during the KT-10-19 cruise. T. Shiozaki analyzed data sets of satellite and climatological current field. S. Takeda analyzed concentration of dissolved iron. S. Itoh performed numerical experiments. T. Kodama and F. Hashihama determined nutrient concentration. T. Shiozaki prepared the manuscript with contributions from all co-authors.

Acknowledgements. We thank J. Ishizaka, the captains, crew members, and participants on board the T/V Nagasaki-maru and $\mathrm{R} / \mathrm{V}$ Tansei-maru cruises for their cooperation at sea. Thanks also to K. Hayashizaki for his support in use of the mass spectrometer at Kitasato University, to A. Takeshige and J. Hirai for their valuable comments on biology in the Kuroshio, and to T. Kitahashi for his suggestion on statistical analyses. Comments from two anonymous reviewers greatly improved the paper. We appreciate NASA ocean color processing group for providing the chl $a$ data set and Japan Oceanographic Data Center for ADCP data set. This research was financially supported by MEXT grant on Priority Areas (18067006 \& 21014006) and by Innovative Areas (24121001, 24121005, \& 24121006) and by Grant-in-Aid for JSPS Fellows (25-7341).

Edited by: K. Suzuki

\section{References}

Bell, P. R. F., Elmetri, I., and Uwins, P.: Nitrogen fixation by Trichodesmium spp. in the central and northern Great Barrier Reef lagoon: relative importance of the fixed-nitrogen load, Mar. Ecol.-Prog. Ser., 186, 119-126, 1999.

Brown, M. T., Landing, W. M., and Measures, C. I.: Dissolved and particulate $\mathrm{Fe}$ in the western and central North Pacific: Results from the 2002 IOC cruise, Geochem. Geophy. Geosy., 6, Q10001, doi:doi:10.1029/2004GC000893, 2005.

Capone, D. G., Zehr, P. J., Paerl, H. W., Bergman, B., and Carpenter, E. J.: Trichodesmium, a globally significant marine cyanobacterium, Science, 276, 1221-1229, 1997.

Chen, C. T. A.: Distributions of nutrients in the East China Sea and the South China Sea connection, J. Oceanogr., 64, 737-751, 2008.

Chen, Y. L. L., Chen, H. Y., Tuo, S. H., and Ohki, K.: Seasonal dynamics of new production from Trichodesmium $\mathrm{N}_{2}$ fixation and nitrate uptake in the upstream Kuroshio and South China Sea basin, Limnol. Oceanogr., 53, 1705-1721, 2008.

Chen, Y. L. L., Chen, H. Y., Lin, Y. H., Yong, T. C., Taniuchi, Y., and Tuo, S. H.: The relative contributions of unicellular and filamentous diazotrophs to $\mathrm{N}_{2}$ fixation in the South China Sea and the upstream Kuroshio, Deep-Sea Res. Pt. I, 85, 56-71, 2014.

Dabundo, R., Lehmann, M. F., Treibergs, L., Tobias, C. R., and Altabet, M. A.: The contamination of commercial ${ }^{15} \mathrm{~N}_{2}$ gas stocks with ${ }^{15} \mathrm{~N}$-labeled nitrate and ammonium and consequences for nitrogen fixation measurements, PLoS one, 9, e110335, doi:10.1371/journal.pone.0110335, 2014.

Dupouy, C., Benielli-Gary, D., Neveux, J., Dandonneau, Y., and Westberry, T. K.: An algorithm for detecting Trichodesmium surface blooms in the South Western Tropical Pacific, Biogeosciences, 8, 3631-3647, doi:10.5194/bg-8-3631-2011, 2011.

Großkopf, T., Mohr, W., Baustian, T., Schunck, H., Gill, D., Kuypers, M. M. M., Lavik, G., Schmitz, R. A., Wallace, D. W. R., and LaRoche, J.: Doubling of marine dinitrogen-fixation rate based on direct measurements, Nature, 488, 361-364, 2012. 
Hasegawa, D., Lewis, M. R., and Gangopadhyay, A.: How islands cause phytoplankton to bloom in their wake, Geophys. Res. Lett., 36, L20605, doi:10.1029/2009GL039743, 2009.

Hashihama, F., Furuya, K., Kitajima, S., Takeda, S., Takemura, T., and Kanda, J.: Macro-scale exhaustion of surface phosphate by dinitrogen fixation in the western North Pacific, Geophys. Res. Lett., 36, L03610, doi:10.1029/2008GL036866, 2009.

Isobe, A.: Recent advances in ocean-circulation research on the Yellow Sea and East China Sea shelves, J. Oceanogr., 64, 569-584, 2008.

Itoh, S., Yasuda, I., Nishikawa, H., Sasaki, H., and Sasai, Y.: Transport and environmental temperature variability of eggs and larvae of the Japanese anchovy (Engraulis japonicus) and Japanese sardine (Sardinops melanostictus) in the western North Pacific estimated via numerical particle-tracking experiments, Fish. Oceanogr., 18, 118-133, 2009.

Jickells, T. D., An, Z. S., Andersen, K. K., Baker, A. R., Bergametti, G., Brooks, N., Cao, J. J., Boyd, P. W., Duce, R. A., Hunter, K. A., Kawahata, H., Kubilay, N., LaRoche, J., Liss, P. S., Mahowald, N., Prospero, J. M., Ridgwell, A. J., Tegen, I., and Torres, R.: Global iron connections between desert dust, ocean biogeochemistry, and climate, Science, 308, 67-71, 2005.

Johnson, K. S., Chavez, F. P., and Friederich, G. E.: Continentalshelf sediment as a primary source of iron for coastal phytoplankton, Nature, 398, 697-700, 1999.

Johnson, K. S., Boyle, E., Bruland, K., Coale, K., Measures, C., Moffett, J., Aguilar-Islas, A., Barbeau, K., Bergquist, B., Bowie, A., Buck, K., Cai, Y., Chase, Z., Cullen, J., Doi, T., Elrod, V., Fitzwater, S., Gordon, M., King, A., Laan, P., Laglera-Baquer, L., Landing, W., Lohan, M., Mendez, J., Milne, A., Obata, H., Ossiander, L., Plant, J., Sarthou, G., Sedwick, P., Smith, G.J., Sohst, B., Tanner, S., Van den Berg, S., and Wu, J.: The SAFe iron intercomparison cruise: an international collaboration to develop dissolved iron in seawater standards, Eos, 88, 131-132, 2007.

Kodama, T., Furuya, K., Hashihama, F., Takeda, S., and Kanda, J.: Occurrence of rain-origin nitrate patches at the nutrientdepleted surface in the East China Sea and the Philippine Sea during summer, J. Geophys. Res., 116, C08003, doi:10.1029/2010JC006814, 2011.

Kustka, A., Sañudo-Wilhelmy, S., Carpenter, E. J., Capone, D. G., and Raven, J. A.: A revised estimate of the iron use efficiency of nitrogen fixation, with special reference to the marine cyanobacterium Trichodesmium spp. (Cyanophyta), J. Phycol., 39, 12-25, 2003.

Lin, I.-I., Hu, C., Li, Y.-H., Ho, T.-Y., Fischer, T. P., Wong, G. T. F., Wu, J., Huang, C.-W., Chu, D. A., Ko, D. S., and Chen, J.-P.: Fertilization potential of volcanic dust in the low-nutrient low-chlorophyll western North Pacific subtropical gyre: Satellite evidence and laboratory study, Global Biogeochem. Cy., 25, GB1006, doi:10.1029/2009GB003758, 2011.

Liu, X., Furuya, K., Shiozaki, T., Masuda, T., Kodama, T., Sato, M., Kaneko, H., Nagasawa, M., and Yasuda, I.: Variability in nitrogen sources for new production in the vicinity of the shelf edge of the East China Sea in summer, Cont. Shelf Res., 61-62, 23-30, 2013.

Mahaffey, C., Michaels, A. F., and Capone, D. G.: The conundrum of marine $\mathrm{N}_{2}$ fixation, Am. J. Sci., 305, 546-595, 2005.

Mahowald, N. M., Engelstaedter, S., Luo, C., Sealy, A., Artaxo, P., Benitez-Nelson, C., Bonnet, S., Chen, Y., Chuang, P. Y., Cohen,
D. D., Dulac, F., Herut, B., Johansen, A. M., Kubilay, N., Losno, R., Maenhaut, W., Paytan, A., Prospero, J. M., Shank, L. M., and Siefert, R. L.: Atmospheric iron deposition: Global distribution, variability, and human perturbations, Annu. Rev. Mar. Sci., 1, 245-278, 2009.

Marumo, R. and Asaoka, O.: Trichodesmium in the East China Sea 1. Distribution of Trichodesmium thiebautii GOMONT during 1961-1967, J. Oceanogr. Soc. Japan, 30, 298-303, 1974.

Mather, R. L., Reynolds, S. E., Wolff, G. A., Williams, R. G., Torres-Valdes, S., Woodward, E. M. S., Landolfi, A., Pan, X., Sanders, R., and Achterberg, E. P.: Phosphorus cycling in the North and South Atlantic Ocean subtropical gyres, Nat. Geosci., 1, 439-443, 2008.

Matsuno, T., Lee, J. S., Shimizu, M., Kim, S. H., and Pang, I. C.: Measurements of the turbulent energy dissipation rate $\varepsilon$ and an evaluation of the dispersion process of the Changjiang Diluted Water in the East China Sea, J. Geophys. Res., 111, C11S09, doi:10.1029/2005JC003196, 2006.

McGowan, J. A.: Oceanic biogeography of the Pacific, in: The Micropaleontology of Oceans, Cambridge University Press, Cambridge, UK, 3-74, 1971.

McKinna, L. I. W., Furnas, M. J., and Ridd, P. V.: A simple, binary classification algorithm for detection of Trichodesmium spp. within the Great Barrier Reef using MODIS imagery, Limnol. Oceanogr.-Meth., 9, 50-66, 2011.

Miyazawa, Y., Zhang, R., Guo, X., Tamura, H., Ambe, D., Lee, J. S., Okuno, A., Yoshinari, H., Setou, T., and Komatsu, K.: Water mass variability in the western North Pacific detected in a 15year eddy resolving ocean reanalysis, J. Oceanogr., 65, 737-756, 2009.

Mohr, W., Großkopf, T., Wallace, D. W. R., and LaRoche, J.: Methodological underestimation of oceanic nitrogen fixation rate, PLoS one, 5, e12583, doi:10.1371/journal.pone.0012583, 2010.

Montoya, J. P., Voss, M., Kähler, P., and Capone, D. G.: A simple, high-precision, high-sensitivity tracer assay for $\mathrm{N}_{2}$ fixation, Appl. Environ. Microb., 62, 986-993, 1996.

Moore, C. M., Mills, M. M., Langlois, R., Milne, A., Achterberg, E. P., LaRoche, J., and Geider, R. J.: Relative influence of nitrogen and phosphorus availability on phytoplankton physiology and productivity in the oligotrophic sub-tropical North Atlantic Ocean, Limnol. Oceanogr., 53, 291-305, 2008.

Moore, C. M., Mills, M. M., Achterberg, E. P., Geider, R. J., LaRoche, J., Lucas, M. I., McDonagh, E. L., Pan, X., Poulton, A. J., Rijkenberg, M. J. A., Suggett, D. J., Ussher, S. J., and Woodward, E. M. S.: Large-scale distribution of Atlantic nitrogen fixation controlled by iron availability, Nat. Geosci., 2, 867-871, 2009.

Moore, C. M., Mills, M. M., Arrigo, K. R., Berman-Frank, I., Bopp, L., Boyd, P. W., Galbraith, E. D., Geider, R. J., Guieu, C., Jaccard, S. L., Jickells, T. D., LaRoche, J., Lenton, T. M., Mahowald, N. M., Marañon, E., Marinov, I., Moore, J. K., Nakatsuka, T., Oschlies, A., Saito, M. A., Thingstad, T. F., Tsuda, A., and Ulloa, O.: Processes and patterns of oceanic nutrient limitation, Nat. Geosci., 6, 701-710, 2013.

Obata, H., Karatani, H., and Nakayama, E.: Automated determination of iron in seawater by chelating resin concentration and chemiluminescence detection, Anal. Chem., 65, 1524-1528, 1993. 
Obata, H., Karatani, H., Matsui, M., and Nakayama, E.: Fundamental studies for chemical speciation of iron in seawater with an improved analytical method, Mar. Chem., 56, 97-106, 1997.

Saito, M. A., Bertrand, E. M., Dutkiewicz, S., Bulygin, V. V., Moran, D. M., Monteiro, F. M., Follows, M. J., Valois, F. W., and Waterbury, J. B.: Iron conservation by reduction of metalloenzyme inventories in the marine diazotroph Crocosphaera watsonii, P. Natl. Acad. Sci. USA, 108, 2184-2189, 2011.

Shiozaki, T., Furuya, K., Kodama, T., and Takeda, S.: Contribution of $\mathrm{N}_{2}$ fixation to new production in the western North Pacific Ocean along $155^{\circ}$ E, Mar. Ecol.-Prog. Ser., 377, 19-32, 2009.

Shiozaki, T., Furuya, K., Kodama, T., Kitajima, S., Takeda, S., Takemura, T., and Kanda, J.: New estimation of $\mathrm{N}_{2}$ fixation in the western and central Pacific Ocean and its marginal seas, Global Biogeochem. Cy., 24, GB1015, doi:10.1029/2009GB003620, 2010.

Shiozaki, T., Furuya, K., Kurotori, H., Kodama, T., Takeda, S., Endoh, T., Yoshikawa, Y., Ishizaka, J., and Matsuno, T.: Imbalance between vertical nitrate flux and nitrate assimilation on a continental shelf: Implications of nitrification, J. Geophys. Res., 116, C10031, doi:10.1029/2010JC006934, 2011.

Shiozaki, T., Kodama, T., Kitajima, S., Sato, M., and Furuya, K.: Advective transport of diazotrophs and importance of their nitrogen fixation on new and primary production in the western Pacific warm pool, Limnol. Oceanogr., 58, 49-60, 2013.
Shiozaki, T., Chen, Y. L. L., Lin, Y. H., Taniuchi, Y., Sheu, D. S., Furuya, K., and Chen, H. Y.: Seasonal variations of unicellular diazotroph groups A and B, and Trichodesmium in the northern South China Sea and neighboring upstream Kuroshio Current, Cont. Shelf Res., 80, 20-31, 2014a.

Shiozaki, T., Ijichi, M., Kodama, T., Takeda, S., and Furuya, K.: Heterotrophic bacteria as major nitrogen fixers in the euphotic zone of the Indian Ocean, Global Biogeochem. Cy., 28, 10961110, 2014b.

Shiozaki, T., Kodama, T., and Furuya, K.: Large-scale impact of the island mass effect through nitrogen fixation in the western South Pacific Ocean, Geophys. Res. Lett., 41, 2907-2913, 2014c.

Wilson, C. and Qiu, X.: Global distribution of summer chlorophyll blooms in the oligotrophic gyres, Progr. Oceanogr., 78, 107-134, 2008.

Zhang, R., Chen, M., Cao, J., Ma, Q., Yang, J., and Qiu, Y.: Nitrogen fixation in the East China Sea and southern Yellow Sea during summer 2006, Mar. Ecol.-Prog. Ser., 447, 77-86, 2012. 